\title{
Effects of prescription drug diversion, misuse and abuse on the health system in eThekwini District, KwaZulu-Natal, South Africa: Key stakeholders' perceptions
}

Buyisile Chibi ( $\sim$ chibuyi@gmail.com )

University of KwaZulu-Natal College of Health Sciences https://orcid.org/0000-0003-1912-8402

Tivani P Mashamba-Thompson

University of KwaZulu-Natal College of Health Sciences

Research article

Keywords: drug diversion, drug misuse, drug abuse, non-medical use

Posted Date: December 4th, 2019

DOl: https://doi.org/10.21203/rs.2.18196/v1

License: (a) This work is licensed under a Creative Commons Attribution 4.0 International License.

Read Full License 


\section{Abstract}

Background: Prescription drug diversion, misuse and abuse is a growing health threat negatively impacting the health care system and individuals globally. Most research has been conducted in highincome-countries. Little is known about prescription drug diversion, misuse and abuse to support anecdotal reports in resource-limited settings. Purpose: The main objective of this study is to determine prescription drug diversion, misuse and abuse practices in eThekwini district from the perspective of the health care providers, law enforcement, pharmacists, drug users and people living with HIV.

Methods: Semi-structured in-depth-interviews were conducted between June-December 2018 among key stakeholders who were purposively sampled in eThekwini district. Thematic analysis was used to identify emergent themes around practices of prescription drug diversion, misuse and abuse.

Results: Five main themes emerged during the interviews: manifestation of drug diversion; consumer's attitude and behaviour; availability of medicines; gaps in the health care system; and lastly challenges and barriers to drug abuse treatment. Accidental addiction, health system gaps and consumer's attitude and behaviours were perceived as significant contributing factors to the problem therefore negatively impacting health care providers and consumers.

Conclusion: The study highlights the emerging practices of prescription drug diversion, misuse and abuse as a serious growing problem occurring through legal and illegal channels to anyone since the addictive medicines are readily available and easily accessible. We recommend a collaborative approach to address prescription drug diversion since the prescriber, dispenser, consumer and law enforcement are involved in the cycle to drug usage.

\section{Introduction}

The United Nations Office of Drugs and Crimes noted analgesics, tranquilizers, stimulants and antibiotics as the commonly misused medicines worldwide (1). Despite that pharmaceuticals play a significant role in healthcare, many recreational drugs were once used or prescribed by medical professionals and later prohibited due to their adverse consequences that could no longer be ignored (2-4). The diversion, misuse and abuse of pharmaceutical products is a growing health threat negatively impacting the health system, individuals, morbidity and mortality rates $(1,5-7)$. Globally, the consumption of recreational drugs such as heroin and cocaine appeared stable whilst the consumption of synthetic and prescription drugs is increasing influenced by their widespread availability, affordability and perceived safety $(1,8,9)$. The estimates for misuse of medicines either obtained over-the-counter and/or by prescription is driven by the prescribing patterns and the retail nature of pharmacies (8). Globally, about 190000 drug-related deaths were attributed to misuse of prescription drugs in 2015 (10). Opioid use disorder and its consequences are serious public health problems (11). Individuals with behavioural practices of opioids misuse may develop dependency, opioid use disorder and sometimes transition to heroin use. Subsequently leading to the increase incidence rates of blood-borne infections such as human 
immunodeficiency virus (HIV), hepatitis B and $\mathrm{C}$ which are prevalent among key populations including injecting drug users $(12,13)$. Worldwide, HIV and opioid use disorder manifest as intersecting epidemics (14). Therefore, hindering the global priority to control the HIV epidemic especially among key populations (15). In South Africa there is limited data on drug diversion, misuse and abuse. The misuse of opioids in the form of codeine containing products has recently being documented as most commonly accessed in local pharmacies $(5,16-22)$. Tolerance, dependence and addiction of codeine can develop very rapidly (11). Whilst, about $80 \%$ of medical professionals lack appropriate knowledge or guidance on prescribing potentially addictive medicines (16). In addition to the stigma and discrimination experienced by people living with HIV (PLWH), some data suggest that they are also affected with chronic pain (23$26)$, thus, predisposing them to frequent use prescription drugs such as opioids $(27,28)$. Although, South Africa's National Strategic Plan for HIV, TB and STIs 2017-2022 is adopted in response to the HIV epidemic, the country is still far to the end of HIV (29).To date, South Africa accounts for about $19 \%$ of global HIV infections (30). Of the 7.9 million people living with HIV in South Africa, the KwaZulu-Natal province owns the highest HIV prevalence in the country of more than 2.1 million people are living with HIV (31). PLWH with opioid use disorder carries a double burden thus bringing complexity for treating and managing both epidemics.

South Africa has a National Drug Master Plan for 2013-2017 that is guided by the Prevention and Treatment of Drug Dependency Act (20 of 1992), and the Prevention of and Treatment for Substance Abuse Act (70 of 2008)(32). However, the drug law, policy, and law enforcement practices serve as barriers to implementing harm reduction strategies in order to fully address substance abuse as well as reduction of drug diversion, misuse and abuse (33). Despite the scrutiny and controversy from local officials, TB HIV Care Organisation has managed to implement the provision of free health services such as harm reduction, opioids substitution therapy and needle syringe provision programme among people who inject drugs at three sites in South Africa i.e. Cape Town, Durban and Nelson Mandela Bay (34). In addition to the HIV burden South Africa is faced with, it is imperative to understand the context of drug diversion, misuse and abuse. To date, research investigating the diversion, misuse and abuse of medicines either obtained over-the-counter or by prescription has been neglected to a large extent $(5,16$, 18-20). As a result, there is little available literature on the prevalence of drug diversion, misuse and abuse to support anecdotal reports in South Africa (22).

In the South African context, HIV control is the $1^{\text {st }}$ priority therefore the main objective of this study is to determine prescription drug diversion, misuse and abuse practices from the perspective of the multisectoral stakeholders in eThekwini district. Key stakeholder to be engaged would be the health care providers, law enforcement officers, pharmacists, current/past drug users and people living with HIV through in-depth interviews. Thus, understanding how each sector contributes, prevent and control the problem of prescription drug diversion, misuse and abuse. The study findings would bring awareness of the existing practices of prescription drug diversion, misuse and abuse to policy makers, health care personnel and lastly to the public. 


\section{Definitions}

In this study, we define drug diversion according to Inciardi et al (2016) as the illegal manner of obtaining or distributing medicines for any use (35). Misuse of medicines is defined according to Casati et al. (2012) includes inappropriate use with or without a health care provider's instructions but clearly not adhering to the dosage instructions, time period or ways of drug administration therefore the risks are more significant than the benefits (36). Lastly, drug abuse is defined according to Akerele et al. (2017) refers to the non-medical use of medicines in quantities that might be fatal (37).

\section{Methods}

\section{Study design}

This is qualitative study that employed semi-structured interview guide to conducted face-to-face in-depth interviews for data collection. We conducted this study was conducted in the period of June and December 2018. We recruited key stakeholders of prescription drug diversion, misuse and abuse in eThekwini district. We defined key stakeholders of prescription drug diversion, misuse and abuse as parties involved in medicine distribution and usage. Through the interviews, data was collected on and practice of prescription drug diversion, misuse and abuse. We used face-to-face, in-depth interviews as they can reveal new information, uncover hidden practices and provide insight into the topic, (38) which is imperative in understanding the perceived practices.

\section{Study setting}

Interviews were conducted with key stakeholders from eThekwini district, KwaZulu-Natal province in South Africa at the time of the interview. The population size of eThekwini district was estimated at 3.7 million in 2016 of which about 1.9 million people are living with HIV (31). One of the key challenges related to eThekwini district health care service provision is the high prevalence of HIV/AIDS and also abuse of drugs and alcohol (39). However, until to date the extent of prescription drug diversion, misuse and abuse in eThekwini district is unknown.

\section{Study participants}

Participants were eligible for the study if they were aged 18 years or older, reside in eThekwini district and were able to give consent to participate in the study. We aimed at enrolling key stakeholders highly likely to have encountered drug diversion, misuse and abuse. Therefore, our sample comprised of the following

key stakeholders: primary health care providers responsible for HIV care, health care providers responsible for drug abuse treatment, pharmacists, law enforcement officers (analysts from the forensic department), past/recovering prescription drug misusers/diverters/abusers and people living with HIV. People living with HIV were chosen since they have numerous experiences with the health care system. We excluded 
those who were unwilling to give consent. Data was collected in English however other languages were permitted in order to allow full expression of participants' views.

\section{Recruitment approach}

Most participants were found through snow balling, referrals and purposive sampling excluding participants from the law enforcement department who were allocated by the commissioner. The above approaches were appropriate for the study due to the sensitive nature of the study topic and questions. Participants were invited to voluntary participate in the study. Invitations and appointments were made with potential participants via emails, text messages, face-to-face meetings or telephonically depending on feasibility. In cases where one agreed to participate in the study, an appointment date was scheduled for face-to-face the interview at their convenient space and time. There were numerous declines from pharmacists due to their busy schedules. Meanwhile all street vendors or dealers of medications declined due to the fear of safety and the thought of being reported to the authorities. The study aimed to interview at least three participants per category until saturation was achieved. The study purpose was explained to the participant and informed consent was obtained before the interview commenced. In this study thematic saturation point was reached after interviewing 18 participants.

\section{Data collection and instruments}

Face-to-face interviews were conducted with each stakeholder. An open-ended interview guide asking questions related to existing practices and factors contributing to prescription drug diversion, misuse and abuse was used. However, the interview guide ensured that certain important aspects related to the topic were addressed during each interview. The interview guide used in our study has been included as an electronic attachment to this paper (see Additional file 1: Appendix 1). The interview guide was developed and modified to suite our study setting however most questions were adapted from several studies conducted in high-income-countries (40). The interview guide was designed to explore the key

stakeholder's views on existing practices of prescription drug diversion, misuse and abuse. Therefore, our approach was an exploratory study.

\section{Procedure}

All interviews were conducted face-to-face with each participant in a private space at different places and time at their convenience. The researcher who conducted face-to-face qualitative data was trained thorough workshops and consultations with experienced researchers in qualitative study designs. Written consent was obtained from all participants prior to the start of the interview. All interviews were conducted in English however other languages were permitted to allow the participants to fully express themselves. Interviews were audio taped with permission and each lasted up to 60 minutes or less depending on the availability of the participant. Participants who were requested to travelled to the interview venue were reimbursed with R50 for their travels. All interviews were transcribed verbatim and 
translated into English in cases were a non-English language was used. The transcripts were analysed thematically using NVivo 12 software (41).

\section{Ethical Considerations}

The data collection process only commenced after obtaining the full ethical clearance from the University of KwaZulu-Natal's Biomedical Research Ethics Committee (Reference No. BE666/17), the KwaZulu-Natal Provincial Department of Health (Reference No. HRKM055/18, KZ_201802_026) and site clearance from all recruitment sites.

\section{Data management, analysis, validity and reliability of analysis}

The audio-taped interviews were transcribed into a Microsoft word document concurrently with data collection process so to allow for better judgement for data saturation. Data saturation point was reached when all participants were no longer giving new information and the study objective was addressed. In cases were a non-English language was used, the transcript was translated into English by the researcher (BC) and two research assistants (TS and SK). All transcripts were validated for accuracy by the researcher (BC), an independent researcher (TPM-T) and an independent research assistant (DD). Data analysis occurred after data collection process. The framework analysis method approach was followed during data analysis $(42,43)$. The main advantage of using this method was that the matrix output will consist of rows (cases), columns (codes) and 'cells' of the summarized data $(42,43)$. Therefore, providing a flexible systematic structure that can easily be manipulated. The disadvantage is categorizing data since this method cannot handle heterogeneous data therefore it is important to collect data that covers similar topics $(42,43)$. Overall this method aimed to generate themes and the procedure for data analysis and the precise steps employed in the qualitative analysis of interviews are summarized in Table 1.

Table 1: Steps undertaken to analyse in-depth interviews using Framework Methodology 


\begin{tabular}{lll}
\hline Stage & Activity & Procedure for analysis \\
\hline 1 & Transcription & - All interviews were transcribed verbatim to a Microsoft \\
& & word document by the researcher (BC) and two research \\
& assistants (TS and SK). \\
& - All transcripts were validated by the researcher (BC), \\
& independent researcher (TPM-T) and independent research \\
& assistant (DD) not participated in transcription of audios. \\
&
\end{tabular}

$2 \quad$ Familiarization with the interview
- Two researchers (BC and TPM-T) listened and familiarised themselves with the collected data by using the audio recordings and transcripts.

- Notes of the key ideas and repeated themes were highlighted and taken.

$3 \quad$ Coding

- The researchers were concerned with addressing specific research questions and analysed the data with that in mind.

- Thus, this was a theoretical thematic analysis.

- Given this, we coded data that was relevant to or captured something interesting about our research question.

- We did not code every piece of text.

- We used open coding since we developed and modified the codes as we worked through the coding process.

- The main aim of coding was to categorize all collected data.

- Coding, searching and retrieving data was facilitated by using NVivo 12 software.

- Two researchers carefully read the transcripts line by line while taking note of paraphrases or label 'code' that were relevant and important.

$4 \quad$ Developing a working analytical framework
- Codes were grouped into categories.

- These categories formed a working analytical framework. 
analytical

framework
- Analytical framework was used to perform indexing of all transcripts using categories and codes.

\begin{tabular}{llr}
\hline $6 \quad$ Charting data & NVivo 12 software was used to generate framework \\
into the & matrices \\
framework & \\
matrix & \\
\hline
\end{tabular}

$7 \quad$ Interpreting the data

- Characteristics of and differences between the data was identified.

- Mapping and interpretation of the connections between categories to explore relationships and/or causality was done.

\section{Results}

\section{Participants characteristics}

Eighteen residents of eThekwini district, KwaZulu-Natal, South Africa consented to participate in the indepth interviews. Table 2 depicts the characteristics of the study population. Participants provided their perceptions of practices of prescription drug diversion, misuse and abuse. Fifty six percent $(n=10)$ of the sample were male, and 44\% $(n=8)$ were female. Participant's age ranged from 19 to 74 years. The sample consisted of three people whom were living with HIV, three analysts from law enforcement, three health care providers from public health clinics, three doctors from drug treatment centres, two pharmacists (one from retail and the other from public health care facility) and lastly four recovering drug users.

Table 2: Participants characteristics for the in-depth interviews conducted in eThekwini district, KwaZulu-Natal 


\begin{tabular}{|c|c|c|c|c|c|}
\hline Participant & Category & Gender & Race & Age & Residence \\
\hline 1 & $\begin{array}{l}\text { Has been living with HIV since } \\
1999\end{array}$ & Female & Coloured & 54 & Durban \\
\hline 2 & $\begin{array}{l}\text { Has been living with HIV since } \\
2003\end{array}$ & Male & Coloured & 59 & Wentworth \\
\hline 3 & $\begin{array}{l}\text { Has been living with HIV since } \\
2003\end{array}$ & Female & Asian & 42 & Merebank \\
\hline 4 & $\begin{array}{l}\text { Has been an analyst with law } \\
\text { enforcement for } 4 \text { years }\end{array}$ & Female & Black & 32 & Pennington \\
\hline 5 & $\begin{array}{l}\text { Has been an analyst with law } \\
\text { enforcement for } 8 \text { years }\end{array}$ & Female & Asian & 32 & Umhlanga \\
\hline 6 & $\begin{array}{l}\text { Has been an analyst with law } \\
\text { enforcement for } 5 \text { years }\end{array}$ & Female & Black & 29 & Amanzimtoti \\
\hline 7 & $\begin{array}{l}\text { Has been a health care } \\
\text { provider since } 1988 .\end{array}$ & Female & Asian & 53 & Asheville \\
\hline 8 & $\begin{array}{l}\text { Has been a health care } \\
\text { provider since } 2014 \text {. }\end{array}$ & Male & Black & 36 & Isipingo beach \\
\hline 9 & $\begin{array}{l}\text { Has been a health care } \\
\text { provider since } 1991 .\end{array}$ & Female & Black & 51 & Marianhilll \\
\hline 10 & $\begin{array}{l}\text { Qualified as a doctor in } 1979 \\
\text { and working in the substance } \\
\text { abuse treatment facility for } 12 \\
\text { years. }\end{array}$ & Male & Asian & 62 & La Lucia \\
\hline 11 & $\begin{array}{l}\text { Qualified as a doctor in } 1972 \\
\text { and working in the substance } \\
\text { abuse treatment facility for } \\
\text { more than } 25 \text { years }\end{array}$ & Male & Asian & 74 & Westville \\
\hline 12 & $\begin{array}{l}\text { Qualified as a doctor in } 1983 \\
\text { and working in the substance } \\
\text { abuse treatment facility since } \\
1992\end{array}$ & Male & Asian & 57 & $\begin{array}{c}\text { Mount } \\
\text { Edgecombe }\end{array}$ \\
\hline 13 & $\begin{array}{l}\text { Has been a pharmacist since } \\
2006 \text {. }\end{array}$ & Male & Asian & 33 & Newlands \\
\hline 14 & $\begin{array}{l}\text { Has been a pharmacist for } 19 \\
\text { years. }\end{array}$ & Male & Asian & 43 & Hillcrest \\
\hline 15 & $\begin{array}{l}\text { He is a recovering drug user, } \\
\text { He used drugs including } \\
\text { prescription drugs for } 6 \text { years }\end{array}$ & Male & Coloured & 20 & $\begin{array}{c}\text { Permanent } \\
\text { residence in } \\
\text { Pietermaritzburg, }\end{array}$ \\
\hline
\end{tabular}




\begin{tabular}{|c|c|c|c|c|c|}
\hline 16 & $\begin{array}{l}\text { He is a recovering drug user. } \\
\text { He used drugs including } \\
\text { prescription drugs for } 5 \text { years }\end{array}$ & Male & Black & 19 & Montclaire \\
\hline 17 & $\begin{array}{l}\text { He is a recovering drug user. } \\
\text { He used drugs including } \\
\text { prescription drugs for } 8 \text { years. }\end{array}$ & Male & Black & 34 & Mayville \\
\hline 18 & $\begin{array}{l}\text { She is a recovering drug user. } \\
\text { She used drugs including } \\
\text { prescription drugs for } \\
13 \text { years. }\end{array}$ & Female & Indian & 34 & Pinetown \\
\hline
\end{tabular}

\section{Participant's understanding of drug diversion, misuse and abuse}

Majority of participants in the health care profession viewed drug misuse as not taking medication as prescribed, using medication for purposes other than medical diagnosis, wrong dose, wrong duration and taking medication not for the appropriate indication. Most participants associated drug abuse with taking drugs in an addictive potential in order to have some sort of high, using drugs at higher doses, using drugs that are highly addictive with addictive potential or physical dependency. Very few participants were familiar with the term "diversion" however some associated drug diversion with using another patient's medication, using multiple facilities to collect medication, distributing drugs illegally, drugs taken for another use or by another user not according to policies and essential drug list (EDL). Interestingly, one participant viewed drug diversion as prescribing drugs while not using policies and protocols.

"Abuse would be that if a patient umm! probably is not taking their medication as prescribed or using other or another patient's medication umm! or just maybe using multiple facilities to take medication, to collect medication from and that term of abusing in that way abusing the health systems as such and misuse probably is not when they are not taking their medication as prescribed, giving medication to people that umm! were they haven't been seen at the health facility. They are actually prescribing medications to those patients issuing medications without a proper prescription. Diversion I'm not too sure really. It's a term that's new to me." (Participant 7, Health care provider)

"Diversion it could be a person addicted or the person dealing with it. It's a person distributing it illegally now my concern is mostly with those who would become addicted to it that means they use it not in the way that it was intended to be used." (Participant 10, Doctor for substance abuse treatment)

"Misuse would be, the wrong dose, for the wrong duration, for not the appropriate indication and things like that. Abuse for me would be when they are taking it in an addictive potential so, where 
they are taking it in order to feel high. Using it at higher doses and also you see the type of drug would come in there. So, things that are highly addictive. Your amphetamines, your opioids things like that they have a central nervous system addictive potential or a physical ability. A physical dependency. Prescription drug diversion, to be honest. I have not come across that term." (Participant 13, Pharmacist)

"You prescribe a drug not using policies and protocols and for the wrong reasons the drug is taken for another use not according to policies and EDL." (Participant 9, Health care provider)

Participants not in the health care profession viewed drug misuse as not taking medication as prescribed, not fully following instructions, using drugs for wrong purposes, inconsistent use, overuse, wrongful intake, overdosing and taking drugs to relax. Meanwhile drug abuse was associated with addiction, dependency, use for recreational purposes and use for wrong reasons and illegal. Interestingly, some participants associated drug abuse with using drugs to sleep, feeling good, getting high and taking things like sugars. Few participants were familiar with the term "diversion" however drug diversion was viewed as drugs manufactured in clandestine laboratories, drugs bought on the street, passing drugs to another person not suited to and asking for medications from others.

"drug diversion... drugs that are manufactured in clandestine laboratories... something that have been bought on the street... Drug misuse, let's take if you were prescribed medication and then they say you have to take it this way and you didn't take it that way so you are misusing the drug. You are not fully following instructions." (Participant 4, Law enforcement)

"Basically, I would say is the wrongful intake of medication. That its prescribed to you and other people think like they either want to abuse it or they run out of their own medication, but they are asking for your medications to supplement their own." (Participant 1, Person living with HIV)

Recovering drug users were able to relate to their experiences and viewed inappropriate drug use as taking drugs to feel nice, unable to cope with normal life without the drug and using drugs to get high. For example, taking ritalin drug while not being diagnosed with attention deficit hyperactivity disorder (ADHD) to get high. Others viewed inappropriate drug use as mixing cough mixtures with cold drinks to get high.

"I think how it makes you feel, cos I know umm! if you are diagnosed with ADHD you put on ritalin and has certain effect on that is helpful but if you not $A D H D$ then you take ritalin then you gonna get high." (Participant 18, Recovering drug user)

"I think it's something like, this thing that is happening nowadays where people mix cough mixtures like bronclear, benylin, different milligrams with cold drinks." (Participant 15, Recovering drug user)

\section{Thematic Framework}

Five themes emerged during the interviews: 
1. Manifestation of drug diversion

a. Extent of prescription drug diversion, misuse and abuse

b. Accidental addiction

2. Consumer's attitude and behaviour

3. Availability of medicines

4. Gaps in the health care system

5. Challenges and barriers to drug abuse treatment

\section{Manifestation of drug diversion}

Participants presented different manifestation of drug diversion, these include the following: surplus prescribed medications; incorrectly prescribed medications; and mixing codeine containing cough mixtures with anti-depressants to boost the effect or taking sleeping tablets to replace heroin effect. A pharmacist described the legal channels of obtaining prescription medication and another participant described how he got involved in diversion.

"It can occur in formal channels as well, where patients are getting doctors to write up prescriptions they don't actually, they are not the end user of that medication." (Participant 13, Pharmacist)

"These people could not access, they used to ask me. Why are you asking me to get the beta pain tablets? The pharmacy does not want to give us. The mother and daughter used a pack per day". (Participant 2, Person living with HIV)

"So your doctor refuse to write you another script so you go looking on the street and, on the streets, they not going to sell you morphine tablets they are gonna give you heroin and that's often how clients and other people start using heroin is to compensate for morphine." (Participant 18, Recovering drug user)

\section{a. Extent of prescription drug diversion, misuse and abuse}

Most participants viewed drug diversion, misuse and abuse as a serious growing problem occurring everywhere to anyone. Drug diversion, misuse and abuse was mostly observed in private facilities. Despite, measures put in place in facilities, people have strategies to prescription drug diversion, misuse and abuse. Two participants specifically mentioned pain medication as the commonly misused drug class.

"In South Africa and in most developed countries it is prescription drugs. It's a growing epidemic. Sometimes, I feel that maybe a bigger epidemic than the illicit drugs... in eThekwini there is a lot of pain tablets abuse especially the poly drugs." (Participant 12, Doctor for substance abuse treatment) 
"That's a big problem in my private practice. Beside those drugs what we see mainly is codeine. Mainly codeine, codeine dependent you know the cough mixtures and the pain tablets." (Participant 11 , Doctor for substance abuse treatment)

\section{b. Accidental addiction}

Most participants described accidental addiction as one of the leading problems that puts vulnerability to consumers. Pre-existing conditions such as pain, predisposes consumers to continuously use painkillers and subsequently develop into an addiction problem.

"Well, they start, they probably take it you know like codeine and the pethidines and all. They probably take it for a genuine headache when they start getting headaches and because they can get over the counter. They think it's just a minor medication. Whenever they get headache now and again. Instead of taking paracetamol or panado they take umm! codeine with it and eventually get addicted or sometimes they can't sleep they take a sleeping tablet the doctor gives them. I give them four tablets but ones they find that they get a nice sleep with these drugs they want it all the time. That's how the addiction starts." (Participant 11, Doctor for substance abuse treatment)

"I was put on morphine tablets for my hip pain just before I had my hip replacement so the doctor write a script and he says am only going to give you this for 3 months, but then after 3 months you have been taking this morphine three times a day for 3 months do they honestly don't think that you gonna be addicted to this someway." (Participant 18, Recovering drug user)

"Circumstances will be a pre-existing condition like pain they have been prescribed is strong painkiller by the doctor for example. They might have been in an accident. Maybe traumatic accident at that point, maybe they might have needed pethidine shot at the hospital to keep under control. There after it becomes an addictive substance." (Participant 14, Pharmacist)

\section{Consumer's attitude and behaviour}

Participants raised concerns about the consumers' attitude and behaviour towards health care providers when they require more prescription drugs to treat or cure their conditions. It was reported that consumers become aggressive, demanding, asking for specific drugs. It was also noted that most consumers who are addicted to prescription or over the counter drugs are in denial of their addiction problem.

"Doctors cannot afford the time per patient to see... because patients are very demanding as well, they become very aggressive. And so doctors feel like to avoid the conflict they would prescribe and if they prescribe it... a lot of the time where these treatments get used, they are prescribed not on an assessment of the doctor but because the patient is asking for it." (Participant 13, Pharmacist) 
Health care providers and pharmacists felt that their profession is been put in difficult situation and disrespected most of the time by consumers who are addicted to prescription drugs.

"You get one to two patients who you can see they come regularly, and they bully you to give them the tablet if you don't give it to them, they go to the next doctor until they find somebody." (Participant 11 , Doctor for substance abuse treatment)

"You have issues were the patients says, "but the doctor prescribed it and I need it." so it puts you at a difficult position." (Participant 13, Pharmacist)

"I got to the point where panado or gen-payne, all those types of things were not helping me, so I decided not to disclose to the doctor that I had a history of addiction". (Participant 18, Recovering drug user)

\section{Availability of medicines}

All participants believed that medicines are readily available and accessed everywhere either via legal or illegal channels through facilities or dealers and emphasised that there is no need of a physical location. Most drug misusers prefer using the cheapest and easily accessible drugs, which can be obtained overthe-counter. It was also reported that illegal drug venders are also sell drugs during social grant collection targeting elderly people and introducing inappropriately packaged and unlabelled medicines.

"You get from dealers that get from pharmacies or whoever, that we can get from very easily and over the counter in pharmacies." (Participant 15, Recovering drug user)

"When it is pension time... when you just passing by you see pills, they look like stilpane some are capsules in transparent plastics." (Participant 4, Law enforcement analyst)

Participants perceive that medicinal drugs were cheaper compared with illegal drugs.

"For some people that I know they go for the cheapest drugs and its easier accessible you can just get it over the counter." (Participant 15, Recovering drug user)

"That drug is much expensive drug, this is cheaper, so price comes in." (Participant 12, Doctor for substance abuse treatment)

\section{Gaps in the health care system facilitating drug diversion, misuse and abuse}

Majority of participants had perceptions of gaps in the health care system at various dimensions. In the public sector, there were issues of consultation time, negligence and no proper guidelines contributing to diversion. Meanwhile the private sector was money driven therefore influencing diversion. 
"If its public it is usually time and negligence. If I think of all my interaction with pharmacist or pharmacist assistant they are talking with the person next to them or behind or looking at their phones and they are really not looking at the file and the prescription, not really not engaging much with the patient and so the patient become a problem rather than the reason for their job." (Participant 1, Person living with HIV)

"The medical profession is over regulated to a point where doctors and pharmacists will be looking at other avenues of obtaining money." (Participant 14, Pharmacist)

"It's the doctor's role going into the backgrounds. Lots of patients complain about the doctor's interaction." (Participant 12, Doctor for substance abuse treatment)

Within the health system, health care providers viewed their prescribing patterns as inappropriate.

"Very bad. We shouldn't even be prescribing but I stopped in fact I refuse to prescribe in my rooms. I refused to." (Participant 11, Doctor for substance abuse treatment)

"I think within the facility environment, us as prescribers so you find that we prescribe antibiotics where else the patient doesn't need that antibiotic it does happen." (Participant 8, Health care provider)

Majority of participants believed that medicines were easily accessed in pharmacies since pharmacies do not question consumers during purchase.

"Whenever I feel like going to the pharmacy to get medication, no question asked I will be given the medication." (Participant 8, Health care provider)

"You get from dealers that get from pharmacies or whoever, that we can get from very easily and over the counter pharmacies, some pharmacies don't ask you for it they just give it to you over the counter." (Participant 15, Recovering drug user)

\section{$\underline{5 .}$ Challenges and barriers to drug abuse treatment}

Drug abuse is difficult to treat when patients don't take ownership of the underlined problem. Barriers such as inadequate knowledge of how treatment works, health systems barriers with pharmacies were by even after confrontation some pharmacies continued issuing the addictive products was the main concerned mentioned by drug users.

"Is very difficult to treat because they are in denial. They won't accept the fact that they are addicted to any because it's an over the counter. Lots of these things you buy from the chemist, so they don't believe it's addictive you know." (Participant 11, Doctor for substance abuse treatment)

"If you taking methadone, and taking heroin it is like doing nothing. You are flushing methadone into the toilet, because how is it going to work while you are smoking. That's what happened last time, 
that's why I didn't manage to use methadone by myself." (Participant 17, Recovering drug user)

"My mom had to actually go to most of the pharmacies and showed them a picture of me and said they should to stop selling me drugs and stuff. But they still sold it to me." (Participant 15, Recovering drug user)

Participants recommended methadone or opioid substitution therapy as treatment including harm reduction interventions. Some drug users receiving treatment favoured the out-patient treatment which allowed them to face the reality of the outside environment, barriers to treatment and the ability to address them daily.

"I feel very strong toward it, it helped me. I went to six or seven rehabs, they were all excellent based. That didn't do anything for me, when I came back few weeks later, I was back on drugs. Methadone is the only thing that really helped me, obviously with my deep wish to stop. You need to be able to want to stop then the medication work for you., if you want to but if you don't want to stop you will find a million reasons." (Participant 18, Recovering drug user)

"Here, we come daily and go home later. For the first three to four months on treatment yes, I did cheat. I was smoking. Until I understood the concept of harm reduction. Smoking is not the problem. The problem is when you can no longer control your life." (Participant 16, Recovering drug user)

\section{Discussion}

To our best knowledge, this is the first study to provide an in-depth qualitative understanding of the existing practices of prescription drug diversion, misuse and abuse involving stakeholders from both medical and non-medical backgrounds in eThekwini district. The results suggest that drug diversion, misuse and abuse include both prescription and over-the-counter drugs and is a growing public health problem occurring to anyone through legal and illegal channels but mostly observed in private facilities. Despite being unfamiliar with the scientific terms, most participants knew what drug diversion, misuse and abuse entailed. However, accidental addiction is viewed as one of the leading problems that set vulnerability among medicinal drug consumers especially consumers with pre-existing conditions such as pain or addiction history. This study also revealed the prevalent manifestation of drug diversion practices such as patients receiving incorrectly or inappropriately prescribed medications; mixing codeine containing cough formulations with other substances to boost the drug effect, consumption of sleeping tablets to replace heroin effect as well as illegal drug vending of inappropriately packaged and unlabelled medicines. Adding to the problem, health care providers were challenges by the consumers' attitude and behaviours like being aggressive, bullying, demanding, in denial, dishonest and requesting for specific medicines. Prevailing gaps in the health care system also drives drug diversion and misuse. Public health care facilities are perceived to be mostly challenged with insufficient consultation time, negligence and lack of proper guidelines meanwhile private health care facilities are money driven. 
Although evidence reports that the availability $(5,16)$ and accessibility $(44-47)$ of medicines contributes to drug diversion, misuse and abuse, different manifestation of drug diversion are still prevalent. A study by Wells et al. (2018), agrees to our findings that drug misuse is not impacted by being aware and knowledgeable of the potential drug risks (17). Despite that the misuse of codeine-containing products was prevalent, our study has revealed other medicinal drugs with sedation properties which were diverted for illegal use in cases where illegal drugs were unavailable. Therefore, putting drug users at increased risk of drug overdose since the legal drugs would need to be used in higher doses than normal. Although literature has shown that revenue generation predispose most drug stores to sell medicines to clients even without a doctor's prescription (44-46). The reported accidental addiction might stem out from the fact that health care providers are challenged with disparities such as lack of specialized trainings $(5,20)$ and lack of institutional guidelines (48). This study has also shown that consumer's attitude and behaviour as an additional challenge faced by health care providers. This translate into poor protocol implementation for most health care providers who shun away from conflicts with patients or costumers at pharmacy and weak enforcement of regulations and policies has being reported (16). On other hand, consumers' denial and dishonesty adds to the burdened health system gaps such as lack of screening tools (16), lack of monitoring systems (18), poor supervision (16) therefore perpetuating drug diversion problem.

\section{Strengths and limitations}

This study is the first in eThekwini district to highlight practices of prescription drug diversion, misuse and abuse from the perspectives of key stakeholders. It has presented novel drivers of prescription drug diversion, misuse and abuse such as consumer's attitude and behaviours probable in worsening the problem and a barrier to prevention of drug diversion, misuse and abuse. The participants recruited in this study varied in age, gender, race and occupation. It also included experienced health care professionals who are faced with the drug diversion problem daily. Moreover, this study was able to find participants to response to a study that raised a sensitive topic although conducting research about practices of drug diversion, misuse and abuse was a great risk since the law views it as illegal (32). We acknowledge limitations of the study, given the small sample size for each category due to challenges with recruitment and getting consent to participate in the study. Despite, the assurance of confidentiality, privacy and anonymity of data, most people feared of their safety since law views drug diversion as illegal. Most pharmacists in retail practice and all street vendors declined invitations. The study had to use referrals, snowballing sampling techniques as well as building trust. A single researcher (BC) conducted all interviews therefore this might bring bias however an interview guide was used so to guide the conversation. Lastly, the study was conducted in eThekwini district, therefore the findings are not generalizable across KwaZulu-Natal province.

\section{Recommendations}


While the country is still in the midst of HIV/AIDS epidemic, it's of importance to pay attention to emerging public health threats such as prescription drug diversion, misuse and abuse so to develop proper and tailormade strategies to curb problem. Furthermore, addressing drug diversion, misuse and abuse would also address blood borne diseases especially Hepatitis B, Hepatitis C and the human immunodeficiency virus. We recommend future studies to further investigate each identified practice in order to gain more insight into the problem. We also recommend that policy makers should consider a collaborative approach involving all stakeholders affected by drug diversion, misuse and abuse since awareness and knowledge of potential drug risks alone is ineffective.

\section{Conclusion}

This study qualitatively describes practices of prescription drug diversion, misuse and abuse in eThekwini district. Prescription drug diversion and misuse is an emerging public threat with accidental addiction, health care system gaps and consumer's attitude and behaviours leading the problem therefore negatively impacting health care providers and consumers. We recommend a collaborative approach to address prescription drug diversion since the prescriber, dispenser, consumer and law enforcement are involved in the cycle to drug usage.

\section{Declarations}

\section{Ethics approval and consent to participate}

The University of KwaZulu-Natal's Biomedical Research Ethics Committee (Reference No. BE666/17), the KwaZulu-Natal Provincial Department of Health (Reference No. HRKM055/18, KZ_201802_026) and site clearance from all recruitment sites were obtained prior to data collection. All participants consented before data collection resumed.

\section{Consent for publication}

Not applicable

\section{Availability of data and material}

The datasets generated and analysed during the current study are not publicly available since this is a PhD study under examination.

\section{Competing interests}

None declared

\section{Funding}


University of KwaZulu-Natal for financial support, recourses and materials. National Research Foundation for financial support.

\section{Authors' contributions}

$\mathrm{BC}$ and TPM-T conceptualized and designed the study. BC conducted literature search, data collection. $\mathrm{BC}$ and TPM-T analysed data and interpreted results. BC prepared the first manuscript draft including figures and tables which were reviewed by TPM-T several times until ready for submission. $P$

\section{Acknowledgements}

The authors wish to acknowledge the participation of the following institutions/ organisations: Human Sciences Research Council, KwaZulu-Natal Department of Health, South African Police Service, TB HIV Care Organisation, Jullo centre, South African National Council on Alcoholism and Drug Dependence and Assisted Recovery Centres of Africa as well all study participants and research assistants.

\section{References}

1.Cheah YK, Chong YW. Factors influencing medication label viewing in Malaysia. Glob Health Promot. 2018;25(1):63-72.

2.Goldstein RA, DesLauriers C, Burda A, Johnson-Arbor K, editors. Cocaine: history, social implications, and toxicity: a review. Seminars in diagnostic pathology; 2009: Elsevier.

3.Smith DE. Lysergic acid diethylamide: An historical perspective. Journal of Psychedelic Drugs. 1967;1(1):1-5.

4.United Nations Office on Drugs Crime. Preventing Amphetamine-type Stimulant Use Among Young People: A Policy and Programming Guide. United Nations Publications; 2007. Report No.: 9211482232.

5.Carney T, Wells J, Parry CDH, McGuinness P, Harris R, Van Hout MC. A comparative analysis of pharmacists' perspectives on codeine use and misuse - a three country survey. Subst Abuse Treat Prev Policy. 2018;13(1):12.

6. Wazaify M, Abood E, Tahaineh L, Albsoul-Younes A. Jordanian community pharmacists' experience regarding prescription and nonprescription drug abuse and misuse in Jordan-An update. Journal of Substance Use. 2017;22(5):463-8.

7.Cooper RJ. Over-the-counter medicine abuse-a review of the literature. Journal of substance use. 2013;18(2):82-107.

8.Cooper RJ. Over-the-counter medicine abuse - a review of the literature. Journal of substance use. 2013;18(2):82-107. 
9.United Nations Office on Drugs Crime. The non-medical use of prescription drugs: policy direction issues. United Nations New York; 2011.

10.Merz F. United Nations Office on Drugs and Crime: World Drug Report 2017. 2017. SIRIUS-Zeitschrift für Strategische Analysen. 2018;2(1):85-6.

11.National Academies of Sciences. The National Academies Collection: Reports funded by National Institutes of Health. Washington (DC): National Academies Press (US), Copyright 2019 by the National Academy of Sciences. All rights reserved.; 2019.

12.National Institute on Drug Abuse (NIDA) Medications to Treat Opioid Use Disorder 2018 [Available from: https://www.drugabuse.gov/node/pdf/21349/medications-to-treat-opioid-use-disorder.

13.Paquette $\mathrm{CE}$, Pollini RA. Injection drug use, $\mathrm{HIV} / \mathrm{HCV}$, and related services in nonurban areas of the United States: a systematic review. Drug and alcohol dependence. 2018;188:239-50.

14.Oldfield BJ, Muñoz N, McGovern MP, Funaro M, Villanueva M, Tetrault JM, et al. Integration of care for HIV and opioid use disorder. AIDS. 2019;33(5):873-84.

15.UNAIDS. Global AIDS update 2019: Communities at the centre 2019.

16.Foley M, Carney T, Rich E, Dada S, Mburu C, Parry C. A study of medical professionals' perspectives on medicines containing codeine in South Africa. S Afr J Psychiatr. 2018;24:1162.

17.Wells JS, Bergin M, Van Hout MC, McGuinness P, De Pleissisc J, Rich E, et al. Purchasing Over The Counter (OTC) Medicinal Products Containing Codeine - Easy Access, Advertising, Misuse and Perceptions of Medicinal Risk. J Pharm Pharm Sci. 2018;21(1):30049.

18.Van Hout MC, Rich E, Dada S, Bergin M. "Codeine Is My Helper": Misuse of and Dependence on Codeine-Containing Medicines in South Africa. Qual Health Res. 2017;27(3):341-50.

19.Van Hout MC, Norman I, Rich E, Bergin M. Experiences of Codeine Use, Misuse and Dependence: Application of Liese and Franz's Cognitive Developmental Model of Substance Abuse. Behav Cogn Psychother. 2017;45(3):238-52.

20.Parry CDH, Rich E, Van Hout MC, Deluca P. Codeine misuse and dependence in South Africa: Perspectives of addiction treatment providers. S Afr Med J. 2017;107(5):451-6.

21.Dada S, Harker Burnhams N, Van Hout MC, Parry CD. Codeine misuse and dependence in South Africa -learning from substance abuse treatment admissions. S Afr Med J. 2015;105(9):776-9.

22.Chibi B, Torres NF, Sokhela ZP, Mashamba-Thompson TP. Risk factors for prescription drug diversion among people living with HIV: a systematic scoping review. Int J Evid Based Healthc. 2019. 
23.Merlin JS, Zinski A, Norton WE, Ritchie CS, Saag MS, Mugavero MJ, et al. A conceptual framework for understanding chronic pain in patients with HIV. Pain Pract. 2014;14(3):207-16.

24.Surratt HL, Kurtz SP, Levi-Minzi MA, Cicero TJ, Tsuyuki K, O'Grady CL. Pain treatment and antiretroviral medication adherence among vulnerable HIV-positive patients. AIDS Patient Care STDS. 2015;29(4):18692.

25.Miaskowski C, Penko JM, Guzman D, Mattson JE, Bangsberg DR, Kushel MB. Occurrence and characteristics of chronic pain in a community-based cohort of indigent adults living with HIV infection. $J$ Pain. 2011;12(9):1004-16.

26.Cunningham CO. Opioids and HIV infection: from pain management to addiction treatment. Topics in antiviral medicine. 2018;25(4):143.

27.Isenberg SR, Maragh-Bass AC, Ridgeway K, Beach MC, Knowlton AR. A qualitative exploration of chronic pain and opioid treatment among HIV patients with drug use disorders. J Opioid Manag. 2017;13(1):5-16.

28.Liu B, Liu X, Tang SJ. Interactions of Opioids and HIV Infection in the Pathogenesis of Chronic Pain. Front Microbiol. 2016;7:103.

29.SANAC. Let our actions count: South Africa's national strategic plan for HIV, TB and STIs 2017-2022. South African Natl AIDS Counc. 2017;1:1-132.

30.UNIADS. Global AIDS update 2019-Communities at the centre 2019 [Available from: https://www.unaids.org/en/resources/documents/2019/2019-global-AIDS-update.

31.eThekwini District AIDS Council Quarter 1, 2017/2018 Report.

32.The South African Drug Master Plan 2013-2017 [08 August 2019]. Available from: https://www.gov.za/sites/default/files/gcis_document/201409/national-drug-master-plan2013-17.pdf.

33.Csete J, Kamarulzaman A, Kazatchkine M, Altice F, Balicki M, Buxton J, et al. Public health and international drug policy. Lancet (London, England). 2016;387(10026):1427-80.

34.TB HIV CARE 2018 Annual Report [Available from: https://www.tbhivcare.org/annual-reports/.

35.Inciardi JA, Surratt HL, Kurtz SP, Burke JJ. The diversion of prescription drugs by health care workers in Cincinnati, Ohio. Subst Use Misuse. 2006;41(2):255-64.

36.Casati A, Sedefov R, Pfeiffer-Gerschel T. Misuse of medicines in the European Union: a systematic review of the literature. Eur Addict Res. 2012;18(5):228-45.

37.Akerele E, Olupona T. Drugs of Abuse. Psychiatr Clin North Am. 2017;40(3):501-17. 
38.Malterud $\mathrm{K}$. The art and science of clinical knowledge: evidence beyond measures and numbers. Lancet (London, England). 2001;358(9279):397-400.

39.Gumede-Moyo S, Filteau S, Munthali T, Todd J, Musonda P. Implementation effectiveness of revised (post-2010) World Health Organization guidelines on prevention of mother-to-child transmission of HIV using routinely collected data in sub-Saharan Africa: a systematic literature review. Medicine. 2017;96(40):e8055. doi: 10.1097/MD.0000000000008055.

40.Key Informant Interview and Focus Group Sample Questions [Available from: https://bha.health.maryland.gov/OMPP/Documents/SampleFGandKII_Questions.pdf.

41.Castleberry A. NVivo qualitative data analysis Software; QSR International Pty Ltd. Version 10, 2012. Am J Pharm Educ. 2014;78(10.5688).

42.Gale NK, Heath G, Cameron E, Rashid S, Redwood S. Using the framework method for the analysis of qualitative data in multi-disciplinary health research. BMC Medical Research Methodology. 2013;13:117-.

43.Srivastava A, Thomson SB. Framework analysis: a qualitative methodology for applied policy research. 2009.

44.Shirzadeh E, Shomoossi N, Abdolahzadeh H. Topical Anesthetic Misuse in Patients Admitted to Sabzevar Eye Clinic in Iran. Acta Facultatis Medicae Naissensis. 2016;33(4):287-94.

45.Wang X, Peng D, Wang W, Xu Y, Zhou X, Hesketh T. Massive misuse of antibiotics by university students in all regions of China: implications for national policy. Int $\mathrm{J}$ Antimicrob Agents. 2017;50(3):441-6.

46.Peng $D$, Wang $X, X u Y$, Sun $C$, Zhou $X$. Antibiotic misuse among university students in developed and less developed regions of China: a cross-sectional survey. Glob Health Action. 2018;11(1):1-7.

47.Yaylaci S, Tosun O, Sahin O, Genc AB, Aydin E, Demiral G, et al. Misuse of levothyroxine and the rate of achieving target thyroid-stimulating hormone in levothyroxine treatment. Biomed Res. 2017;28(6):26615 .

48.Mun Kit L, Pauline Siew Mei L, Sri Ponnampalavanar SSL, Syed Omar SF, Taib NA, Yusof MY, et al. Antibiotics in surgical wards: use or misuse? A newly industrialized country's perspective. J Infect Dev Ctries. 2015;9(11):1264-71. 